\title{
Road to evolutionary and institutional economics in Japan
}

\section{A personal memoire of the decade of founding the Japan Association for Evolutionary Economics}

\author{
Kiichiro Yagi ${ }^{1}$
}

Published online: 19 May 2018

(C) Japan Association for Evolutionary Economics 2018

\section{Foundation of the Japan Association for Evolutionary Economics}

The Japan Association for Evolutionary Economics (JAFEE) was founded on March 28,1997 , following two initiator meetings in the previous year. Taking into account all those who joined the two foundation meetings, the total membership announced was 490.

To our regret, JAFEE could not increase its membership since then, which still remains about 430. Many of the initial members who were sympathetic toward the Association, but not so serious in its direction, left the Association in a few years. Still, we feel apologetic that we could not develop our activities well enough to attract them.

However, during the course of a quarter century since its foundation, JAFEE has been able to provide an open forum to various streams of heterodox economists in Japan, which was useful not only for economists, but also researchers in other fields such as biology, computer simulation, and econo-physicists. The Association

This note first describes the author's involvement in founding the Japan Association for Evolutionary Economics along with his colleagues. It then reveals the background of the author's move to commit to this project. This recollection concludes with the author's general judgment of the state of evolutionary economics in Japan in the early 21 st century.

\section{Kiichiro Yagi}

yagi@econ.setsunan.ac.jp

1 Setsunan University, Neyagawa, Osaka, Japan 
also developed several unique projects proposing a rethink on economics and other related social sciences. ${ }^{1}$

At present, more than half of the JAFEE members are from the generation that joined the association after its foundation. Thus, I suppose that it would be interesting to recollect the process that led to its foundation and the circumstances then, along with my personal reminiscences related to this project.

The initiative of founding JAFEE came from a group of economists of Kyoto University who were not happy with the then state of economics. After obtaining the agreement of several influential scholars from other universities to join the organizing committee, this group issued their first appeal for founding a society for "evolutionary economics" by the end of March 2016. I attach the English translation of this appeal as an appendix to this note. The appeal had unexpectedly strong repercussions, with the number of supporters surpassing 200 in 2 months, and continuing to increase successively.

The core of the Kyoto group comprised the trio of Satoshi Sechiyama, Kazuo Yoshida, and the author of this memoire. While the foundation meeting nominated Sechiyama as the first president of JAFEE, Yoshida and I assumed the task of general secretary and treasurer jointly. I remember that evening when the group came to an agreement on the necessity of a new academic society for heterodox economists in Japan. However, the society found it difficult to find an appropriate name comprehensive enough to cover the various groups and refreshing enough to motivate participants to join their explorations. We examined several names, but could not finalize any. Finally, Sechiyama proposed the term "evolutionary economics." Sechiyama began his research from the post-Keynesian perspective, and, after exploring the structural changes and innovations, focused on the emerging streams of "evolutionary economics." Initially, I had in mind a term that would imply an "institution" or so. However, the "evolutionary" and institutional economics approaches have various sorts of similarities. Since the Thorstein Veblen era, the proponents of old institutionalism in the United States have not hesitated to describe their approach as "evolutionary." The new academic society founded by a group of European heterodox economists in 1988 added the adjective "evolutionary" to their name. ${ }^{2}$ Furthermore, Sechiyama's approach of close collaboration with the "evolutionary" direction in several branches of natural sciences was very convincing. Thus, I supported his proposal. I assume that Yoshida, who was always interested in the application of nonlinear dynamics to socio-economic affairs, would have a good reason to adopt this proposal. We included this term in the name of the society to be born, "Shinka Keizai Gakkai" (Association for Evolutionary Economics), which at first sounded very clumsy to the polite Japanese for the academic term. However, by the time we met the next morning, the apprehension we had about the term on the previous day had completely gone. We reconfirmed our choice and started to organize the work of JAFEE.

\footnotetext{
${ }^{1}$ The launching of the Evolutionary and Institutional Economics Review in 2004 as an open international journal was of course one. We launched this project following several other publications. Another was the U-Mart project launched in 2005, which simulated and analyzed the fluctuations in the artificial market comprising heterogeneous agents. See Yoshinori Shiozawa, Yoshihiro Nakajima, Hiroyuki Matsui, Yusuke Koyama, Kazuhisa Taniguchi, Fumihiko Hashimoto, Artificial Market Experiments with U-MartSystem, Springer, 2008.

2 That is, the European Association of Evolutionary Political Economy.
} 
The first initiators' meeting of the JAFFE was held on May 25, 1996, at the Rakuyu Kaikan of the Kyoto University, with approximately 60 attendees. This meeting approved the organizing committee after adding several scholars to the original members, and discussed the organization, direction, and process of the foundation.

The second initiators' meeting held on September 21, 1996, approved the draft of the constitution and the program of the foundation meeting (March 28-29, 1997, Kyoto). After considering the organizational issues, a panel discussion was held on the topic, "What Is Evolutionary Economics?" The essential parts of six presentations at this panel meeting were published in a commercial journal of the publisher Yuhikaku (Shosai no Mado) in a series, and contributed much to the diffusion of the JAFEE foundation. ${ }^{3}$

The first foundation meeting was held the next year on March 27-28 at the Kyodai-Kaikan (Kyoto). More than 200 researchers participated in this meeting. Economists of various streams who would never have met in other academic occasions gathered there. The president of Kyoto University, Prof. Hiroo Imura, sent greetings to the foundation, and several blessing messages received from overseas associations were read out. At the plenary English session, Richard Nelson (Columbia University), Ulrich Witt (Max Planck Institute, Jena), and Fumio Kodama (University of Tokyo) delivered lectures. Furthermore, about 30 papers were read at the Japanese sessions, whose proceedings were distributed at the registration. The foundation meeting and every session saw feverish discussions.

\section{Personal recollections}

As for me, the idea of a new heterodox academic association occurred several years before its realization; to be exact, it was in September 1989, when I attended the first annual conference of the European Association for Evolutionary Political Economy (EAEPE) held at Keswick, Cumbria, UK. I was really fortunate to start my sabbatical year abroad with this meeting, which was held on the very days the historical changes in Europe were beginning to take shape. At the meeting, I met Geoffrey Hodgson, the first general secretary of the EAEPE, and bought the paperback edition of his Economics and Institutions (1988); I translated this book in 1997 with the help of my friends, giving it the title, A Manifesto of Modern Institutional Economics. I then told him about my wish to have a similar society in Japan. He remembered this when he paid a visit to Japan in early 1997 upon our invitation. His lecture tour surely helped our work of organizing the foundation of JAFEE.

I was trained in sociology and political economy during my student days. As with many of my generation, Karl Marx and Max Weber were my heroes. When I acquired my first academic job as a lecturer in the history of economics, I naturally wished to place my heroes and the streams that they represented in the intellectual history of the middle Europe, that is, the German-speaking intellectual world. I

\footnotetext{
3 They were reproduced in the second part of the book edited by JAFEE and published the next year. Chapters of its first part comprised the invited lectures at the plenary session of the foundation meeting. See Appendix II.
} 
focused on the Austrian school of economics to draw the total picture of the history of economics in the German-speaking world from the mid-19th century to the early 20th century, in addition to the German Historical School and Marxian Economics. I found that this school revealed originality in not only its early neo-classist view of a utility maximizer, but also in the peculiar neo-classist evolutionary viewpoint. All the three streams in the German-speaking world, Marxists, Historicists, and Austrians, had their own approach to evolutionary economics.

One year before my sabbatical year, I published my first Japanese book on the history of the Austrian school of economics, and this relieved me a bit of the duty of a historian of economics. The new position I acquired in Kyoto required me to take as the main course political economy and as secondary subject the history of economics. Thus, reviving my interest in theoretical research, I decided to use most of my sabbatical to absorb the new trends of the political economy in Europe and the United States.

My attendance at the Keswick conference was in this context. I obtained information of the conference from my ex-mentor, Prof. Kiyoaki Hirata, who had close contact with the French Regulationists. He himself heard of the conference from Robert Delorme, and he forwarded this information to me. When I met him on my return to Japan, he encouraged me to organize a similar association for institutional economics. I did not know then whether he would agree to the name "evolutionary economics." Our common understanding then was that the name "institutional economics" was appropriate and comprehensive enough to attract discontented economists from the various streams of economics, including the neo-classicists, Marxians, NeoKeynesians, Sraffians, and social or sociological economists. Around this period, "new institutional economics" a la Oliver Williamson and Douglass C. North was attracting the attention of Japanese economists, and Masahiko Aoki was systematizing his Comparative Institutional Analysis. On the other hand, Shigeto Tsuru, a legend economist of post-1945 Japan, revisited the tradition of institutional economics and broadly integrated himself and Marx into "institutional economics". This is the reason why I first thought of "institutional economics" as an appropriate name for the newborn academic society.

When in England, I visited the Science Policy Research Unit, University Sussex (SPRU), and met its ex-director Christopher Freeman to collect some working papers of the unit in the neo-Schumpeterian direction. In May the next year, I attended the Airlie House/Virginia Conference of the International Joseph A. Schumpeter Society (ISA) and met the leading economists in this direction. Later, I met Ulrich Witt in Freiburg, and Allan Lipietz and Benjamin Coriat in Paris.

On my return to Japan, I focused on promoting the international academic exchange of heterodox economists, and attended international conferences such as the EAEPE and ISA. During these years, I met Robert Boyer, Bernard Chavance, Kurt Dopfer, Bertram Schefold, Carsten Herrmann-Pillath, Giovanni Dosi, and others. However, before I found some of my colleagues of the same university had

\footnotetext{
4 Shigeto Tsuru, Institutional Economics Revisited, Cambridge University Press, 1993.
} 
similar ambition, I could not step forward to organize the new society of heterodox economists.

One of my regrets when organizing the work of JAFEE was the lack of close collaboration with biology, although JAFEE had several biologists as members and often invited biologists for lectures at its conferences. In this connection, I would like to recall to our memory the leading scientists of the Ecological Institute of Kyoto University who lost their lives in a sea disaster in 2000 on the Californian Bay; they had promised collaboration with JAFEE. However, what brought together economists and scientists under the umbrella of JAFEE was the "artificial evolution" as well as complexity research. I would not deny the contribution of these linkages to our understanding of the evolutionary process. Still, I miss the vision of a vivid and real evolutionary process that could provide us with real observations of the biotic sphere.

\section{General judgment in the early 21st century}

In 2002, 5 years after the foundation of JAFEE, I had a chance to take an overview of the current situation and the tasks of evolutionary economics. ${ }^{5}$ In my overview, I summarized the "emerging core structure" of evolutionary economics in the following three points.

(1) Dual ontology of real phenomena and informational sphere

The distinction between the real and informational corresponds to that between the phenotype and genotype in evolutionary biology. Although individuals in the real sphere are subject to external conditions and the materials that constitute themselves, the informational patterns they convey are the inherited suffering variations occurring in the informational sphere. This dualism is the source of evolution in the socio-economic area as well.

(2) Population thinking and the micro-macro structure

The unit of evolution is the group of individuals (population) with variations that may be inheritable or not inheritable, or transmittable or not transmittable. In case such a group has distinctive features that are reproduced in their new generation, this group may be comparable to a species in biology. In the field of socio-economics, the composition and relations of such individuals and groups (populations) represent the micro and macro structure of a society.

(3) Changing process with path dependency

The process of change is subject to "cumulative causation." In this process, the features of path dependency are salient. Path dependency may come from socio-economical feedback, such as in the emergence of modes and conventions. It may also come from techno-economical feedback without any mutual subjective influence.

\footnotetext{
5 From 2000 to 2002, I participated in a joint research project on Darwinism, whose leader was Prof. Takashi Sakagami, Institute for Research in Humanities, Kyoto University. My report in this project was included in T. Sakagami ed., Henni-suru Darwinism: Shinkaron to Shakai (Variations of Darwinism: Evolution Theory and Society), Kyoto University Press, 2003.
} 
Furthermore, from the progress made in and outside of JAFEE, I recommend the following for researchers in evolutionary economics.

(1) Wise use of "artificial evolution"

Computer simulation is a very powerful tool to introduce path dependency and micro-macro structure to the analysis of evolutionary process. However, we cannot have an economically meaningful interpretation of the conditions, processes, and results without wide knowledge of the real economic life. We should use the "artificial economic evolution" based on computer simulation wisely since its significance lies in its heuristic sense, and not in the traditional deduction/induction sense.

(2) Historiography as the base

As the well-known QWERTY array case suggests, the real process is often subject to historical path dependency, and is not deterministic. The evolutionary view can rebuild the missing bridge between theory and history. Historical studies that consider the uniqueness of the development and features of the materials concerned form the treasury of the data as well as source of theoretical insights to evolutionary economics.

(3) Governance in evolutionary process

The insight into the evolutionary process, where variations and selections occur to form the criteria of evaluation and selection simultaneously, raises the question of how to govern this process. Although Hayek's criticism of "constructivism" is persuasive, it does not exclude improving the conditions of variations/selections or the priority setting in such processes. The provision of a "platform" or "testbed" in the policy of science and technology represents the former. In the process of transformation of the ex-Soviet bloc nations, a path-shaping guidance corresponding to the latter was implemented. Western countries at first demanded free elections and then imposed the fulfillment of pre-accession conditions to the nations that joined the European Union. ${ }^{6}$ An analysis of the governance structure of the evolutionary process should positively contribute to sound policies.

The above was my tentative judgment for the early 21 st century. Since the two main projects introduced in footnote 2 were then not yet realized, this judgment could be premature. However, I hope that this is still valid to the present situation.

I wrote this note to supplement Geoff's article. I must apologize to the readers for this note that remains only a mix of my personal recollections and official documents.

\section{Appendix I}

Appeal to Join the Association for Evolutionary Economics

\footnotetext{
${ }^{6}$ For a decade, I studied the transition economies and the integration of the Eastern and Southern Middle European countries to Western Europe, organizing several conferences and joint studies. Evolution/ Transition: Evolutionary Perspectives on Transition Economics, 2002, is the proceedings of the conference held on March 27-30 under the authorization of JAFEE. I also co-edited with Prof. Satoshi Mizobata, Institute of Economic Research, Kyoto University, Melting Boundaries: Institutional Transformation in the Wider Europe, Kyoto University Press, 2008.
} 


\section{_ New Approach for a Paradigm Change _- \\ March 1996 \\ Organizing Committee*}

Some say that the collapse of the cold war constellation validated the advantage of capitalism and that the whole world is converging toward a similar institution. This is an old view of the traditional paradigm that prevailed till recently. The contesting views of capitalism vs. socialism corresponded to the age of pax RussoAmericana. However, after the demise of the cold war, a new vision has come to the forefront that recognizes the variety of institutions and focuses on their unique development despite mutual influence. It is the coexistence of a variety of institutions that provides human race with rich possibilities of vital development. This is clear from the fact that the development of the market economy takes diversified forms, differing from country to country and region to region. The structure and mode of market competition change by the day due to successive innovations. The emergence of venture business incorporating new technologies in new organizational forms is exemplary in this context. Thus, we need to view the modern world from a new paradigm, that is, from DETERMINISM to PLURALISM.

All the present institutions, socio-economic systems, knowledge and technology, and forms and rules of organizations are the results of formations proceeding on the path of the past to the present. The uniqueness and capabilities of the present world are features that emerged through a historical process, and the future possibilities are grounded on them. The science of the spirit of PLURALISM must have an intellectual framework investigating endogenous evolution, allowing for random emergence of mutation. Evolutionary economics is the attempt to investigate the mechanism of evolution in social systems, organizations, and technology, and thus to contribute to innovation in economic theory.

Researches in this direction have been made since the 1980s, particularly in fields such as microeconomics, macroeconomics, game theory, economics of firm, institutional economics, political economy, theory of international trade, industrial organization, and technology innovation. They integrate the conditions that were so far considered given in their analyses, to obtain fresh results in each field. Evolutionary economics exploring the mechanism of endogenous evolution of social systems, organizations, and technology enable the scientific analysis of the process that was so far only postulated in the preceding mechanistic theory of economic dynamics. It helps recognize that the coexistence and competition of diversified systems, organizations, and technology can produce rich development and hopefully show a new direction of progress for the global economic society.

In natural sciences too, the investigation into the endogenous formation of systems has attracted the interest of researchers, as shown by the progress in explorations into nonlinearity, self-organization, complexities, and so on. We believe that in economic studies, also we are in the age of quest for new general insights and directions based on scientific explorations into the systems, organizations, and technology. We should form a forum of researchers in those new areas, the Association for Evolutionary Economics. We welcome not only researchers in economics and management science, but also those interested in exploration into the endogenous change 
of systems and institutions in areas of law, education, culture, history, and sociology. We expect much participation of those who are directly involved in the evolution of systems, organizations, and technology, such as natural scientists, researchers in charge of $R \& D$ in business firms, and managers of venture business based on innovative technology and organization. We wish that the newborn interdisciplinary association becomes an exemplary case for the evolution of scientific knowledge. We invite all of you to join this project.

* Members: Yuji Aruka, Jun Ikegami, Kenichi Imai, Kazumi Kurokawa, Yoshinori Shiozawa, Yuichi Shionoya, Katsumi Sugiura, Kotaro Suzumura, Satoshi Sechiyama, Takashi Negishi, Masaaki Hirooka, Masaaki Honma, Takeshi Murota. Kiichiro Yagi, and Kazuo Yoshida

\section{Appendix II}

Contents of, What Is Evolutionary Economics?

Japan Association for Evolutionary Economics, ed., What Is Evolutionary Economics? Yuhikaku, 1998, ix + 181p.

Preface Satoshi Sechiyama

Part I Hopes for Evolutionary Economics

Chap. 1 Viewpoints of Evolutionary Economics

Richard Nelson (Department of Politics, Columbia University)

Chap. 2 Economics and Darwinism

Ulrich Witt (Max Planck Institute, Jena)

Chap. 3 Unlocking the Path Dependency and Option Sharing

- Lessons from the Development of Mega-Technology in Japan-

Fumio Kodama (Center of Advanced Technology Research, University of Tokyo)

Chap. 4 From Noise and Chaos to Complexity

Takashi Ikegami (Graduate School of Comprehensive Culture, University of Tokyo)

Chap. 5 Evolution and Ethics

Soshichi Usui (Faculty of Letters, Kyoto University)

Chap. 6 Game Theory and Evolution

Akira Okada (Kyoto University Institute of Economic Research)

Part II What Is Evolutionary Economics?

Chap. 7 Heritages for Evolutionary Economics

Kiichiro Yagi (Economics Department, Kyoto University)

Chap. 8 Complex Systems and Evolution

Yoshinori Shiozawa (Economics Department, Osaka City University)

Chap. 9 Evaluation of the Evolutionary Game Theory

Yuji Aruka (Faculty of Commerce, Chuo University) 
Chap. 10 Theory of Institutions and its Possibilities

Kazuo Yoshida (Economics Department, Kyoto University)

Chap. 11 Dynamism of Technological Innovation and Evolutionary Economics Masaaki Hirooka (Department of Informatics, Ryutsu Kagaku University)

Chap. 12 Cultural System and Economics of Social Evolution

Jun Ikegami (Economics Department, Fukui Prefecture University)

Afterword Kazuo Yoshida 